\title{
SUBSTÂNCIAS TÂNICAS PRESENTES EM PARTES DA ÁRVORE SABIÁ (Mimosa caesalpiniifolia Benth.) EM PLANTIO COMERCIAL DE 5 ANOS
}

\author{
Tatiane Kelly Barbosa Azevêdo;; Márcia Gabrielle de Almeida Cardoso²; Debora Baiocchi \\ Princivalli Campos 3 ; Dina Garcia Souza ${ }^{4}$, Lucas Jean Nunes ${ }^{5}$; João Paulo Silva Gomes ${ }^{6}$; \\ Anderson Aurelio de Azevêdo Carnaval;; Gualter Guenther Costa Silva ${ }^{8}$.
}

\footnotetext{
1Universidade Federal do Rio Grande do Norte, Macaíba, RN, Brasil, tatianekellyengenheira@hotmail.com

2 Universidade Federal do Rio Grande do Norte, Macaíba, RN, Brasil, marcia.gabrielle@gmail.com

${ }^{3}$ Universidade Federal do Rio Grande do Norte, Macaíba, RN, Brasil, deboraprincivalli@gmail.coml ${ }^{4}$ Universidade Federal do Rio Grande do Norte, Macaíba, RN, Brasil, garcia7dina@gmail.com ${ }^{5}$ Universidade Federal do Rio Grande do Norte, Macaíba, RN, Brasil, lucasjeansnunes@gmail.com

${ }^{6}$ Universidade Federal do Rio Grande do Norte, Macaíba, RN, Brasil, jpsilgom@hotmail.com.br 7 Universidade Federal do Rio Grande do Norte, Macaíba, RN, Brasil, carnaval552@gmail.com ${ }^{8}$ Universidade Federal do Rio Grande do Norte, Macaíba, RN, Brasil, gualtermve@gmail.com
}

RESUMO: O sabiá (Mimosa caesalpiniifolia Benth.) é uma espécie arbórea, nativa do bioma Caatinga, de grande abrangência e de relevante interesse econômico, pelo seu potencial madeireiro e forrageiro. Estudos vem sendo desenvolvidos, buscando espécies da região Nordeste do Brasil com potencial tanífero em função da exploração desordenada sobre o Angico vermelho (Anadenanthera colubrina (Vell.) Brenan) para a exploração da casca e seu uso no curtimento de peles. Baseado nisto, este estudo teve como objetivo, analisar folhas, galhos finos e casca da espécie sabiá, quanto a suas características como produtora de taninos vegetais. Os materiais foram secos ao ar, moídos e classificados, tendo sido utilizada a porção que passou por uma peneira de 16 "mesh" (1,00 mm) e ficou retida numa de 60 "mesh" (0,25 mm). Para as extrações foram utilizados 25 gramas de cada material. $O$ extrato obtido foi passado em peneira de 150 "mesh" (0,105 mm), em tecido de flanela, filtrado em funil de vidro sinterizado de porosidade 2 e concentrado. Em seguida, foram determinados o teor de sólidos totais (TST) e o teor de taninos condensados (TTC). Todas as partes da planta analisadas apresentaram taninos, porém, a casca da planta apresentou maior concentração de taninos condensados (8,38\%) e menor quantidade de não taninos (1,22\%), indicando que dentro do extrativo, há uma quantidade de tanino considerável. Conclui-se que a casca do sabiá apresenta potencial como produtora de taninos vegetais, sendo necessário a realização de estudos para identificar seu potencial no curtimento de peles dentre outras formas de utilizações.

PALAVRAS-CHAVE: Floresta seca, Produto Florestal não Madeireiro, Taninos vegetais. 


\title{
TANNIC SUBSTANCES PRESENT IN PARTS OF (MIMOSA CAESALPINIIFOLIA) IN COMMERCIAL PLANTATION OF 5 YEARS
}

\begin{abstract}
Sabiá (Mimosa caesalpiniifolia Benth.) is an arboreal species, native to the Caatinga biome, of wide range and relevant economic interest due to its potential for logging and fodder. Studies have been carried out to find species from the Northeastern region of Brazil with taniferous potential due to the uncontrolled exploitation of the Angico vermelho (Anadenanthera colubrina (Vell.) Brenan) for the exploitation of the bark and its use in tanning. Based on this, this study had the objective of analyzing leaves, thin branches and bark of the species sabiá, as to its characteristics as a producer of vegetable tannins. The materials were dried, powdered and classified, using the parts that have gone through a sieve of 16 "mesh" $(1.00 \mathrm{~mm})$ and were retained by 60 "mesh" $(0.25 \mathrm{~mm})$. For extractions 25 grams of each material was used. After extraction, the material was passed through a 150 "mesh" (0.105 mm) sieve of flannel tissue and filtered through a sintered glass funnel of porosity 2, and then concentrated. Total solid content was determined (TST), and also the tannin content (TTC). All the parts of the plant analyzed had condensed tannins. However, the bark of the plant showed a higher concentration of condensed tannins (8.38\%) and less amount of non tannins (1.22\%), indicating that inside the extractive there is a quantity of considerable tannin. It is concluded that the bark of the sabiá is potential as a producer of vegetable tannins, and it is necessary to carry out studies to identify its potential in the tanning of furs among other forms of uses.
\end{abstract}

KEYWORDS: Dry forest, Non-timber forest product, Vegetable tannins.

\section{SUSTANCIAS TÁNICAS PRESENTES EN PARTES DEL ÁRBOL SABIÁ (MIMOSA CAESALPINIIFOLIA BENTH.) EN SIEMBRA COMERCIAL DE 5 AÑOS}

RESUMEN: El sabiá (Mimosa caesalpiniifolia Benth.) es una especie arbórea, nativa del bioma Caatinga, de gran alcance y de relevante interés económico, por su potencial maderero y forrajero. Los estudios vienen siendo desarrollados, buscando especies de la región Nordeste de Brasil con potencial tanífero en función de la explotación desordenada sobre el Angico vermelho (Anadenanthera colubrina (Vell.) Brenan) para la explotación de la cáscara y su uso en el curtido de pieles. En base a esto, este estudio tuvo como objetivo, analizar hojas, ramas finas y cáscara de la especie sabia, en cuanto a sus características como productora de taninos vegetales. Los materiales fueron secos al aire, molidos y clasificados, habiendo sido utilizada la porción que pasó por un tamiz de 16 "mesh" (1,00 mm) y quedó retenida en una de 60 "mesh" (0,25 mm). Para las extracciones se utilizaron 25 gramos de cada material. El extracto obtenido fue pasado en criba de 150 "mesh" (0,105 mm), en tejido de franela, filtrado en embudo de vidrio sinterizado de porosidad 2 y concentrado. A continuación, se determinó el contenido de sólidos totales (TST) y el contenido de taninos condensados (TTC). Todas las partes de la 
planta analizadas presentaron taninos, sin embargo, la corteza de la planta presentó mayor concentración de taninos condensados (8,38\%) y menor cantidad de no taninos $(1,22 \%)$, indicando que dentro del extractivo, tanino considerable. Se concluye que la cáscara del sabiá presenta potencial como productora de taninos vegetales, siendo necesario la realización de estudios para identificar su potencial en el curtido de pieles entre otras formas de usos.

PALABRAS CLAVE: Bosque seco, Producto forestal no maderero, Taninos vegetales.

\section{INTRODUÇÃO}

Os taninos vegetais, são substâncias que estão presentes em várias partes da planta, como frutos, sementes, raízes, cerne da madeira e na casca de diversas espécies florestais, e são conhecidos por serem naturais (PAES et al., 2006a; PAES et al., 2006b). Sua utilização vem se tornando abrangente ao longo dos anos em função da preocupação com meio ambiente, já que este, substitui agentes químicos (PAES et al., 2010), a exemplo do furfural (PANSHIN et al., 1962). Seu percentual pode variar entre indivíduos da mesma espécie em função da época de coleta em detrimento da fenologia de algumas plantas (AZEVEDO et al., 2017).

Dentre suas diferentes formas de utilização, se destacam: produção de adesivo de madeira (AZEVEDO et al., 2015), indústria de petróleo como agentes de suspensão, dispersantes e fluidificantes em lama de perfuração, controlando a viscosidade de argilas na perfuração de poços (PANSHIN et al., 1962), fabricação de tintas e adesivos especiais para madeira (VIEIRA et al., 2014) e derivados, em países como Austrália e África do Sul (TRUGILHO et al., 1997), além da importância no curtimento de couros e peles (PAES et al., 2006), bastante empregado no Nordeste do Brasil. Recentemente foi comprovada a eficiência dos taninos de algumas espécies como ação inibitória contra diferentes espécies de microrganismos cariogênicos, sem causar toxicidade sobre células eucarióticas ou atividade mutagênica (ARAÚjO et al., 2017).

A espécie florestal mais importante como produtora de tanino vegetal no Brasil é a Acacia mearnsii De Wild., uma espécie exótica, popularmente conhecida como acácia negra, sendo ela bastante 
cultivada no estado do Rio Grande do Sul, onde em 2016 atingiu uma produtividade de 195.913 t de casca para produção de taninos (IBGE, 2017). Na região Nordeste, o angico-vermelho (Anadenanthera colubrina var. cebil (Griseb.) Altschul), é a única fonte de taninos utilizada, sendo empregada nos curtumes tradicionais locais, que exploram exclusivamente suas cascas (PAES et al., 2006a). Essa prática de extração extrativista, é realizada sem o manejo adequado, o que quase sempre leva a morte da planta, em função de seu anelamento no momento da coleta da casca. Dados do IBGE (2017) mostram que em 2016 houve uma quantidade produzida de 95 t de casca de angico vermelho, valor esse 15,2\% inferior ao ano anterior. Paes et al. (2006) já relatavam, o desaparecimento desta espécie na paisagem do Semiárido Nordestino.

Em busca de alternativas para a redução do impacto sobre o angico vermelho, vários pesquisadores estão identificando nas espécies nativas do bioma Caatinga, possíveis produtoras de taninos vegetais (AZEVEDO et al., 2017;
PAES et al., 2006; CALEGARI et al., 2016; LOPES et al., 2015). Algumas espécies estão sendo analisadas, a exemplo da jurema-preta (Mimosa tenuiflora (Willd.) Poir.), cajueiro (Anacardium occidentale $L_{\text {L) }}$, jurema-vermelha (Mimosa arenosa (Willd.) Poir.), sabiá (Mimosa caesalpinïfolia Benth.), entre outras. Atualmente, esta região vem investindo em plantios florestais para fins madeireiros, como exemplo espécies do gênero Eucalyptus e a espécie Acacia mangium (Willd.), que apesar de serem exóticas, vem apresentando um bom desenvolvimento, e apresentam boa quantidade de taninos condensados (TRUGILHO et al., 2003; UCELLA FILHO et al., 2017).

O sabiá (Mimosa caesalpiniifolia Benth.) se destaca no Nordeste como uma das principais fontes de estacas para cercas, além de fonte de energia (carvão e lenha), em função da alta densidade $\left(0,87 \mathrm{~g} \mathrm{~cm}^{-3}\right)$ e teor de carbono fixo de aproximadamente (73\%) (RIBASKI et al., 2003). A identificação de taninos condensados nas partes desta planta, deverá agregar ainda mais valor a espécie analisada. 
Alguns estudos mostram que algumas partes da árvore, podem conter um teor de taninos condensados que justifiquem a sua extração a nível comercial, como foi encontrado no trabalho de Paes et al., (2010) no fruto sem sementes de angico vermelho (10,70\%), podendo ser um grande aliado a sustentabilidade das espécies produtoras de taninos. Baseado nisto, este estudo tem como objetivo, analisar o teor de sólidos totais, de taninos condensados e não taninos presentes nos galhos finos, folhas e casca do sabiá.

\section{MATERIAL E MÉTODOS}

trabalho foi conduzido em Área de Experimental Florestal, com plantio da espécie M. caesalpiniifolia que atualmente encontra-se com 60 meses, localizada no município de Macaíba, Rio Grande do Norte. De acordo com a classificação de Köppen, o clima local é caracterizado como tropical chuvoso (transição entre os tipos As e BSw), apresentando estação chuvosa de outono e inverno, com temperatura média de $27^{\circ} \mathrm{C}$, sendo a máxima de $32^{\circ} \mathrm{C}$ e a mínima de $21^{\circ} \mathrm{C}$, umidade relativa média anual de 76\% e precipitação pluviométrica variando entre 863,7 e 1.070,7 mm (IDEMA, 2013).

Seleção das árvores

A partes das árvores foram coletadas em uma Área Experimental Florestal, com plantio da espécie M. caesalpiniifolia com 60 meses, localizada no município de Macaíba, RN. De acordo com a classificação de Köppen, o clima local é caracterizado como tropical chuvoso (transição entre os tipos As e BSw), apresentando estação chuvosa de outono e inverno, com temperatura média de $27^{\circ} \mathrm{C}$, umidade relativa média anual de $76 \%$ e precipitação pluviométrica variando entre 863,7 e 1.070,7 mm (IDEMA, 2013). As coletas foram realizadas em maio de 2017, onde foram utilizadas 5 (cinco) plantas do plantio de sabiá, que foram selecionadas em função do seu vigor, sendo escolhidas aquelas com ausência de ataque de pragas e doenças. Destas plantas foram realizadas medições de altura total e diâmetro a altura do peito (DAP). 
Foram coletados os ramos, com diâmetro inferior a $2 \mathrm{~cm}$, aleatoriamente na copa de cada árvore, com o auxílio de podão, e aproximadamente $1,0 \mathrm{~kg}$ de folhas verdes foram coletadas dos mesmos ramos. As cascas (porção viva das mesmas) foram retiradas no tronco, galhos e ramos com diâmetro de até $2 \mathrm{~cm}$. Os Materiais foram cortados com auxílio de um facão, em fragmentos menores, de aproximadamente $3 \times 2 \mathrm{~cm}$. Os materiais foram secos ao ar, moídos em moinho do tipo Willey, para obter um material de menor granulometria. Para evitar o aquecimento acentuado das facas do moinho, o que poderia causar alterações na composição química dos taninos, o processo de moagem foi realizado com paradas constantes, sempre que as partes cortantes do moinho ficavam aquecidas.

Para as análises, os materiais foram classificados, sendo utilizada a porção que passou pela peneira de 16 "mesh" (1,00 mm), e ficou retida na de 60 "mesh" $(0,25$ mm). A serragem obtida foi homogeneizada e o teor de umidade (base seca) determinado, para permitir os cálculos, em base seca, do teor de taninos presentes em cada amostra.
As substâncias tânicas contidas nos materiais foram extraídas em água destilada. Para as extrações foram tomadas, de cada material, três amostras de $25 \mathrm{~g}$ de material seco.

As amostras foram transferidas para balões de fundo chato com capacidade de $500 \mathrm{~mL}$, aos quais foram adicionados 250 mL de água destilada (relação 1:10 p/v) e submetidas à fervura, sob refluxo, por duas horas. Cada amostra foi submetida a duas sequências de extrações, a fim de se retirar à máxima quantidade de extrativos presentes.

Após cada extração, o material foi passado em uma peneira de 150 "mesh" $(0,105 \mathrm{~mm})$ e em um tecido de flanela, para a retenção de partículas de serragem. O extrato obtido foi homogeneizado e filtrado em funil de vidro sinterizado de porosidade 2. Em seguida, foi concentrado para $250 \mathrm{~mL}$ pela evaporação da água ao empregar um aparelho tipo Soxhlet. Após a concentração três alíquotas de $50 \mathrm{~mL}$ foram retiradas de cada extrato. Duas alícotas foram utilizadas para a determinação do teor de taninos condensados (TTC) e uma foi evaporada em estufa a $103 \pm 2{ }^{\circ} \mathrm{C}$ por 48 horas, para 
a determinação da porcentagem de teor de sólidos totais (TST) (Equação 1).

$$
\operatorname{TST}(\%)=\underline{M i-M f} * 100
$$

$$
\text { Mi }
$$

Em que:

TST = teor de sólidos totais, em porcentagem; $\mathrm{Mi}=$ massa inicial, em gramas; e Mf = massa final, após secagem, em gramas.

Para a determinação do TTC presente em cada amostra foi empregado o método de Stiasny, descrito por Guangcheng et al. (1991), com algumas modificações. Para tanto, aos $50 \mathrm{~mL}$ do extrato bruto foram adicionados $4 \mathrm{~mL}$ de formaldeído $(37 \% \mathrm{~m} / \mathrm{m})$ e $1 \mathrm{~mL}$ de $\mathrm{HCl}$ concentrado. Cada mistura foi submetida à fervura sob refluxo por 30 minutos. Nessas condições, os taninos formam complexos insolúveis que podem ser separados por filtragem simples. Para isso empregou-se filtro de papel posto em funil de Büchner de $10 \mathrm{~cm}$ de diâmetro e $4 \mathrm{~cm}$ de profundidade. O material retido no filtro foi seco em estufa a $103{ }^{\circ} \mathrm{C} \pm 2{ }^{\circ} \mathrm{C}$ por 24hs em seguida calculou-se o índice de Stiasny (Equação 2).
Em que:

$l(\%)$ = Índice de Stiasny, em porcentagem; M1 = Massa de sólidos em $50 \mathrm{~mL}$ de extrato; M2 = Massa do precipitado tanino-formaldeído.

A quantidade de taninos presente em cada amostra foi obtida ao multiplicar o índice de Stiasny pelo teor de sólidos totais (Equação 3).

$\mathrm{TTC}(\%)=\mathrm{TST} * \mathrm{I} / 100$

Em que:

TTC (\%) = Teor de taninos condensados, em porcentagem; TST = Teor de sólidos totais (Equação 1); I = Índice de Stiasny (Equação 2).

O teor de não taninos foi obtido pela diferença entre o teor de sólidos totais e o teor de taninos condensados obtido de cada amostra.

Para a avaliação dos resultados foi utilizado um delineamento inteiramente casualisado, tendo as análises estatísticas sido processadas por meio do Sistema de Análises Estatísticas e Genéticas (SAEG), desenvolvido pela Central de Processamentos de Dados da Universidade Federal de Viçosa, sendo analisados o teor de sólidos totais (TST), índice de Stiasny e teor de taninos condensados (TTC) em 
várias partes da planta da espécie não taninos, deferiram significativamente estudada.

entre as partes analisadas da planta

Por se tratar de dados em (Tabela 1). A maior quantidade de teor de porcentagens, os valores foram umidade foi encontrada nas folhas. O TST, transformados em arcsen[raiz quadrada (valores em porcentagem/100)]. Esta transformação, sugerida por Steel e Torrie (1980), é necessária para homogeneizar as variâncias e permitir a análise dos dados. Na análise e avaliação dos ensaios foi empregado o teste de agrupamento de médias de Scott-Knott a $5 \%$ de significância.

\section{RESULTADOS E DISCUSSÃO}

As plantas escolhidas no interior da que expressa a quantidade de extrativos totais presentes nas amostras analisadas, foi maior nas folhas, e menor nos galhos finos. Nas folhas encontram-se os nutrientes da planta provenientes do solo (RAVEN et al., 2001). Esses dados também foram encontrados para as árvores de angico vermelho (Anadenanthera colubrina . var. cebil (Griseb.) Altschul) (29,30\%) (PAES et al., 2010) e jurema preta (Mimosa tenuiflora Benth. ) (24,58\%) (SILVA et al., 2017).

parcela, apresentaram altura média de 5,59m e DAP médio de 5,14cm. Os valores de teor de índice de Stiasny, e teores de

Tabela 1. Comparações entre médias (\%) do teor de umidade (TU), teor de sólidos totais (TST), índice de Stiasny (I), teor de taninos condensados (TTC) e teor de não taninos (TNT) para as partes analisadas da planta.

\begin{tabular}{cccccc}
\hline \multirow{2}{*}{ Partes da planta } & \multicolumn{5}{c}{ Teores médios nas partes analisadas } \\
\cline { 2 - 5 } & TU(\%) & TST(\%) & I (\%) & TTC(\%) & TNT(\%) \\
\hline Folhas & $112 \mathrm{a}$ & $18,61 \mathrm{a}$ & $30,73 \mathrm{c}$ & $5,71 \mathrm{~b}$ & $12,92 \mathrm{a}$ \\
Galhos finos & $49 \mathrm{~b}$ & $8,96 \mathrm{~b}$ & $51,15 \mathrm{~b}$ & $4,38 \mathrm{~b}$ & $4,58 \mathrm{~b}$ \\
Casca & $53 \mathrm{~b}$ & $9,18 \mathrm{~b}$ & $91,27 \mathrm{a}$ & $8,38^{\mathrm{a}}$ & $1,22 \mathrm{c}$ \\
\hline
\end{tabular}

As médias seguidas por uma mesma letra, para cada parâmetro avaliado, não difere estatisticamente (ScottKnott; $p>0,05)$. 
Na reação de Stiasny são precipitados somente taninos do tipo flavanol através da condensação com formaldeído em meio ácido, sendo esses produtos de alto peso molecular e de difícil dissolução, onde quanto maior o número de Stiasny, maior será a quantidade de polifenóis (taninos) presentes nos extratos (GUANGCHENG et al., 1991; MORI, 1997; GONÇALVES et al., 2003). A casca foi a parte da planta que apresentou maior quantidade no índice de Stiasny (91,27\%), sendo este valor superior ao obtido por Gonçalves e Lelis (2001), que foi de aproximadamente 20\% com árvores com idade entre 8-12 anos. Isto pode ter ocorrido em função da idade das plantas, ou do período de coleta das cascas, uma vez que Paes et al. (2006b) constatou que o índice de Stiasny variou com as fenofases da planta e posições no tronco de jurema preta (Mimosa tenuiflora).

Esses valores também foram superiores ao encontrado para a madeira (62\% a 65\%) da mesma espécie segundo Gonçalves et al., (2003), que vem sendo estudada como potencial produtora para adesivo de madeira (GONÇALVES et al., 2003). teor de taninos condensados, que indica a proporção de taninos presente nos materiais analisados, foi maior na casca do tronco, e as demais partes não diferiram significativamente. $\bigcirc$ valor de TTC encontrado nesta pesquisa foi superior ao obtido Gonçalves e Lelis (2001), que foi de $2 \%$.

teor de não taninos foi maior nas folhas, a qual foi extraída a maior quantidade de substâncias, porém elas apresentaram os menores índices de Stiasny, isto significa que as substâncias encontradas apresentam pouco tanino. Caldas et al., (2010) identificaram que as folhas das plantas de sabiá apresentam composição química (proteína bruta, material mineral, fibras) três vezes mais que os ramos finos.

\section{CONCLUSÃO}

Conclui-se que todas as partes da planta analisadas apresentaram taninos vegetais, porém, a casca apresentou maior teor de taninos condensados, o que justificaria sua extração a nível comercial. Sendo necessário estudos para verificar sua eficiência no curtimento de peles em função da demanda de 
taninos pelos curtumes tradicionais da Região Nordeste do Brasil, e demais utilidades.

\section{AGRADECIMENTOS}

Laboratório de Tecnologia de

Produtos Florestais, Programa de PósGraduação em Ciências Florestais, Universidade Federal do Rio Grande do Norte, Escola Agrícola de Jundiaí, Fapern/Capes.

\section{REFERÊNCIAS}

ARAÚJO, J. S. C.; CASTILHO, A. R. F.; LIRA, A. B.; PEREIRA, A. V.; AZEVEDO, T. K. B.; BRITO COSTA, E. M. M.; PEREIRA, M. S. V.; PESSOA, H. F. L; PEREIRA, J. V. Antibacterial activity against cariogenic bacteria and cytotoxic and genotoxic potential of Anacardium occidentale L. and Anadenanthera macrocarpa (Benth.) Brenan extracts. Archives of Oral Biology. v. 85, p.173-179, 2017.

AZEVEDO, T.K.B.; PAES, J.B.; CALEGARI, L.; NASCIMENTO, J.W.B. Qualidade dos taninos de jurema-preta (Mimosa tenuiflora) para a produção de adesivo tanino formaldeído. Revista Ciência Florestal, Santa Maria - RS, v. 25, n. 2, p. 507-514, 2015.

AZEVEDO, T.K.B.; PAES, J.B.; CALEGARI, L.; SANTANA, G. M. Teor de Taninos Condensados Presente na Casca de Jurema-Preta (Mimosa tenuiflora) em
Função das Fenofases. Floresta e Ambiente. v.24, p.7, 2017.

CALDAS, G. G.; DOS SANTOS, M. V. F.; LIRA JUNIOR, M. A.; FERREIRA, R. L. C.; CUNHA, M. V.; LIRA, M. A.; BEZERRA NETO, E.; GALDINO, A. C. Caracterização morfológica e química de Mimosa caesalpiniifolia submetida à adubação com P. Archivos de Zootecnia, Universidad de Córdoba Córdoba, España .v. 59, p. 529-538, 2010.

CALEGARI, L.; LOPES, P. J. G.; OLIVEIRA, E.; GATTO, D. A.; STANGERLIN, D. M. Quantificação de taninos nas cascas de jurema-preta e acácia-negra. Pesquisa Florestal Brasileira (Impresso), v. 36, p. 6169, 2016.

GONÇALVES, C. A.; LELIS, R. C. C. Teores de taninos da casca e da madeira de cincoleguminosas arbóreas. Floresta e Ambiente, v. 8, n.1, 167-173, 2001.

GONÇASLVES, C. A.; LELIS, R.C. C.; BRITO, E. O.; NASCIMENTO, A. M. Produção de chapas de madeira aglomerada com adesivo Uréiaformaldeído modificado com tanino de mimosa Caesalpiniaefolia bentham (sabiá). Floresta e Ambiente. v.10, p.18. 2003.

GUANGCHENG, Z.; YUNLU, L.; YAZAKI, Y. Extractive yields, Stiasny values and polyflavonoid contents in barks form six acacia species in Australia. Australian Forestry, Queensland, v.554, n.2, p.154156, 1991.

IBGE - INSTITUITO BRASILEIRO DE GEOGRAFIA E ESTATÍSTICA. Produção da extração vegetal e da silvicultura. v. 31, p.55, 2017. 
INSTITUTO DE DESENVOLVIMENTO ECONÔMICO E MEIO AMBIENTE DO RIO GRANDE DO NORTE (IDEMA). Perfil do seu município: Macaíba. IDEMA: Natal, 2013. 21 p. Disponível em: <http://adcon.rn.gov.br/ACERVO/idema/ DOC/DOC000000000016679.PDF>.

Acesso em: 23 maio 2017.

LOPES, P. J. G.; CALEGARI, L.; CALEGARI, C. C. A.; OLIVEIRA, E.; STANGERLIN, D. M.; GATTO, D. A. Produtividade em Casca e Taninos Condensados de Jurema-Preta. Nativa, v. 3, p. 95-101, 2015.

MORI, F.A. Uso de taninos da casca de Eucalyptus grandis para produção de adesivos. 1997. Viçosa. 47 f. Dissertação (Mestrado em Ciência Florestal) Universidade Federal de Viçosa, Viçosa, 1997.

PAES, J. B.; DINIZ, C. E. F.; MARINHO, I. V.; LIMA, C. R. DE. Avaliação do potencial tanífero de seis espécies florestais de ocorrência no Semi-Árido brasileiro. Revista Cerne, Lavras - MG, v.12, p.232238, 2006a.

PAES, J. B.; MARINHO, I. V., LIMA, R. A., LIMA, C. R.; AZEVEDO, T. K. B. Viabilidade técnica dos taninos de quatro espécies florestais de ocorrência no Semiárido brasileiro no curtimento de peles. Revista Ciência Florestal, Santa Maria, v. 16, n. 4, p. 453-462. 2006 b.

PAES, J. B.; SANTANA, G. M.; AZEVEDO, T. K. B.; MORAIS, R. M.; JUNIOR, J. T. C. Substâncias tânicas presente em várias partes da árvore angico-vermelho (Anadenanthera colubrina (Vell.) Brenan. var. cebil (Gris.) Alts.). Scientia Forestalis, Piracicaba, v. 38, n. 87, p. 441 - 447, 2010.
PANSHIN, A.J.; HARRAR, E.S.; BETHEL, J.S.; BAKER, W.J. Forest products: their sources, production, and utilization. 2.ed. New York: McGraw-Hill, 1962. 538p.

RAVEN, H.P.; EVERT, R.F.; EICHHORN, S.E. Biologia vegetal. 6.ed. Rio de Janeiro: Guanabara Koogan, 2001. 906 p.

RIBASKI, J.; LIMA, P. C. L.; OLIVEIRA, V. R.; DRUMOND, M. A. Sabiá (Mimosa caesalpiniifolia): árvore de múltiplo uso no Brasil. Colombo: Embrapa Florestas, 2003. 4p. (Embrapa Florestas. Comunicado Técnico, 104). Disponível em:

$<$ http://www.cnpf.embrapa.br/publica/co muntec/edicoes/com_tec104.pdf>.

Acesso em: 28 setembro 2017.

SILVA, B. R. F.; MOURA, M. C. V.; UCELLA FILHA, J. G. M.; CARNAVAL, A. A. A.; COSTA, T. L. N.; AZEVEDO, T. K. B.; CANTO, J. L.; PAES, J. B. Substâncias tânicas presentes em várias partes da árvore jurema - preta (Mimosa tenuiflora sp.), In: CONGRESSO BRASILEIRO DE CIÊNCIA E TECNOLOGIA DA MADEIRA, 3., Florianópolis, 2017. Anais... Florianópolis: UDESC, set. 2017. ON-LINE.

STEEL, R. G. D.; TORRIE, J. H. Principles and procedures of statistic: a biometrical approach. 2.ed. New York: Mc-Graw Hill, 1980. 633p.

TRUGILHO, P. F.; CAIXETA, R. P.; LIMA, J. T.; MENDES, L. M. Avaliação do conteúdo em taninos condensados de algumas espécies típicas do cerrado mineiro. Cerne, v.3, n.1, p.1-13, 1997.

TRUGILHO, P. F.; MORI, F. A.; LIMA, J. T.; CARDOSO, D. P. Determinação do teor 
de taninos na casca de Eucalyptus spp. Cerne, v. 9, n. 2, p, 246-254, 2003.

UCELLA FILHO, J. G. M.; SILVA, B. R. F.; ALMEIDA, D. M.; MOUSINHO, N.; CARNAVAL, A. A. A.; SILVA, J. P. G.; AZEVEDO, T. K. B., GUENTHER, G. Teor de taninos presentes na casca da árvore Acacia mangium willd em um plantio comercial localizado no nordeste do brasil. In: CONGRESSO BRASILEIRO DE CIÊNCIA E TECNOLOGIA DA MADEIRA, 3., Florianópolis, 2017. Anais... Florianópolis: UDESC, set. 2017.ON-LINE.

VIEIRA, M. C.; LELIS, R. C. C.; RODRIGUES, N. D. Propriedades químicas de extratos tânicos da casca de Pinus oocarpa e avaliação de seu emprego como adesivo.

CERNE (UFLA), v. 20, p. 47-54, 2014. 